Escritores que dibujan. J. K. Rowling y su proyecto creador

Lucas Gagliardi

Boletín de Arte (N.21), e029, abril 2021, ISSN 2314-2502

https://doi.org/10.24215/23142502e029

http://papelcosido.fba.unlp.edu.ar/ojs/index.php/boa

Facultad de Artes. Universidad Nacional de La Plata

La Plata. Buenos Aires. Argentina

\title{
ESCRITORES QUE DIBUJAN \\ J. K. ROWLING Y SU PROYECTO CREADOR
}

\section{WRITERS THAT DRAW}

\section{J. K. ROWLING AND HER CREATIVE PROJECT}

Lucas Gagliardi / lucas.lenguayliteratura@hotmail.com.ar

Instituto Superior de Formación Docente y Técnica N. ${ }^{\circ} 9$

Universidad Nacional de La Plata. Argentina

\section{RESUMEN}

Si bien existen numerosos artistas que han cultivado obras literarias y plásticas en paralelo, poco se ha estudiado el modo en que sus producciones visuales se vinculan con la literaria y viceversa. En este artículo se analiza la relación entre los dibujos y la escritura de J. K. Rowling. Utilizamos elementos de la crítica genética y los estudios comparados para pensar lo que se dicen mutuamente las producciones visuales y literarias de esta autora sobre el universo ficcional de Harry Potter.

\section{PALABRAS CLAVE}

Dibujo; literatura; estudios comparados; proyecto creador

\section{ABSTRACT}

Although several artists who have created literature as well as plastic works exist, such cases have rarely been researched in comprehensive studies. This article analyses the relationship between Rowling's drawings and her literary production. We make use of some concepts drawn from genetic criticism and comparative studies in order to think about the dialogue between her visual and literary work on Harry Potter's fictional world.

\section{KEYWORDS}

Drawing; literature; comparative studies; creative project 
Existen numerosos casos de artistas que han cultivado más de una forma expresiva. Con frecuencia, la historiografía artística y la crítica se concentran en una de esas expresiones más que en las otras, cuando no exclusivamente en una. En el caso particular de la literatura y su campo de estudio solemos encontrar concentración exclusiva en la actividad literaria de estos artistas multifacéticos, quienes pasan a ser identificados como escritores. En parte, esa aproximación resulta un movimiento lógico para la constitución disciplinar, pero cabe interrogarse si tal operación no corre el riesgo de reducir la singularidad expresiva de diferentes personajes a determinados modelos de escritor.

Los estudios literarios comparados han producido trabajos que abordan los vínculos entre sistemas de signos diferentes, principalmente por medio del concepto de intermedialidad (Rajewsky, 2005) y el de traducción (Gabrieloni, 2006, 2009). La mayoría de estos trabajos ha estudiado cómo aparece en determinada producción literaria una obra que proviene de otro código semiótico. En términos de las relaciones transtextuales que definió Gérard Genette (1989), los estudios comparados piensan los vínculos entre obras literarias y visuales desde la intertextualidad. ${ }^{1}$ Son escasos, en cambio, los estudios que abordan esos vínculos de un modo análogo a la intratextualidad (relación entre los diferentes textos/mensajes de un mismo autor). La pregunta de la mayoría de los estudios comparativos sería ¿qué ocurre cuando un escritor recurre a otras obras artísticas? La pregunta que nos interesa es ¿qué ocurre cuando, además de escribir, el mismo artista dibuja? Y, también, ¿qué se dicen mutuamente el dibujo y la escritura de un artista?

Los interrogantes se desprenden del análisis de la producción artística de J. K. Rowling y el universo ficcional de Harry Potter. En este artículo nos aproximamos a su proyecto creador (Bourdieu, 2002) de un modo que busca dar cuenta de los vínculos entre su producción literaria y visual. Nuestra hipótesis sostiene que los dibujos e ilustraciones producidos por Rowling permiten una indagación en su proyecto creador y echan luz sobre diferentes aspectos de los textos literarios como su estética, su construcción del verosímil y sus técnicas narrativas.

\section{ESTUDIAR A LOS ESCRITORES QUE DIBUJAN}

El título de este apartado encierra ya un supuesto que nos interesa desmontar. El sintagma escritores que dibujan conlleva una toma de postura para conceptualizar al artista. Esta denominación implica hacer una concesión al modo en que su obra se presenta en el campo intelectual y cultural. Allí Rowling se presenta como escritora y se la identifica predominantemente como tal, al igual que ocurre con otros artistas con producciones similares. Distinto es el caso de artistas que, activamente, crean y dan a conocer obras inscriptas en diferentes disciplinas. Por consiguiente, no podemos ignorar el juego de fuerzas sociales que incide sobre eso que Pierre Bourdieu (2002) llamaba proyecto creador del artista, ya que este siempre es un "proyecto de ser reconocido" (p. 19) en el campo según unos términos que se moldean en la mediación cultural. Nuestro campo disciplinar es el de los estudios literarios; en consecuencia, nos aproximamos a ese sector de la obra de Rowling compuesto por sus dibujos con el texto literario de por medio.

Son muchos los escritores que se han dedicado a la imagen visual, como se puede advertir con solo hojear el catálogo The Writer's Brush [El pincel del escritor] (2007), de Donald Friedman. En muchos de estos casos, las obras visuales no se relacionan directamente con los escritos literarios de esos artistas (no comparten un tema o personajes), pero cabría pensar en lo que esas pinturas y esculturas podrían decir sobre la literatura de John Updike, Elizabeth Bishop, Hermann Hesse y otros casos recopilados en ese libro. Es más frecuente que la relación entre expresión plástica y escritural de un mismo artista sea abordada cuando se trata de obras integrales, como es el caso de William Blake, John Ruskin y William Morris o, más

1 Genette (1989) la define como "una relación de copresencia entre dos o más textos, es decir, eidéticamente y frecuentemente, como la presencia efectiva de un texto en otro" (p. 10). 
cerca en el tiempo, de la literatura infantil (Nodelman, 1998) y del libro álbum en particular. En este último caso existe una gran cantidad de estudios sobre autores como Isol, Jimmy Liao o Edward Gorey que se dedicaron a crear obras en las cuales la palabra y la imagen poseen un "vínculo de interdependencia" (Miller en Rougeau, 2005, p. 23). Sin embargo, no se trata de artistas que puedan ser clasificados simplemente como escritores; se trata de artistas integrales cuyas obras no son reductibles a una sola rama del arte.

El caso de Rowling se asemeja mucho más a otros artistas que también crearon obras visuales con diferentes grados de circulación pública, casos donde las creaciones visuales forman parte del proceso escritural, aunque no siempre se hayan publicado como parte de la obra literaria: Lewis Carrol, analizado por R. Nichole Rougeau (2005); Federico García Lorca, abordado por José Luis Plaza Chillón (2011); y Violeta Parra, estudiado por Verónica Stedile Luna (2013). Los dibujos de Rowling, como en las obras de los artistas mencionados, muestran un diálogo dentro de su proceso de escritura y, por consecuencia, en el proyecto creador.

\section{ARCHIVO, MATERIALES, OBRA}

Los dibujos de Rowling pueden entenderse como materiales de archivo. Eso es posible desde la perspectiva de la crítica genética, disciplina que nos permite indagar en los procesos creativos. Los estudios geneticistas como el de Stedile Luna (2013) acceden a la producción (escrita) interpretándola como un proceso compuesto por materiales que pueden ser de lo más variados.

Desde esta perspectiva el manuscrito o la copia impresa no se conciben como documentos que certifican el origen de la obra literaria. En todo caso, son documentos con huellas del proceso creativo donde se agitan conflictos del proyecto creador. Los dibujos, fotografías y otros materiales, desde un punto de vista hermenéutico (Lois, 2001), se pueden considerar también como materiales de la génesis y participar del archivo de un escritor. El genetista francés Daniel Ferrer (2007) planteó que el conjunto de pretextos o documentos escritos se encuentra atravesado por relaciones textuales de experimentación, de cambio y de persistencia. En este entramado, las piezas visuales de Rowling, como los dibujos de otros escritores, participan del proceso de creación literaria del mismo modo que cualquier otro documento de planificación textual. La noción de obra también se desdibuja: no sería ya el resultado (por ejemplo, el libro publicado o la pintura exhibida), sino la suma de estados de archivación y lo que entre ellos sucede.

Si bien no podemos profundizar en los pormenores de la noción de archivo y sus implicancias institucionales, queremos señalar algo sobre los estados de archivación. Rowling ha dado a conocer algunos manuscritos originales de sus novelas, pruebas de galera con anotaciones, esquemas y planificaciones de sus novelas, croquis de algunos escenarios como la escuela Hogwarts y también dibujos de personajes y situaciones que realizó en paralelo a la escritura. En todos los casos, se trata de una producción parcialmente pública.

El estado de archivación de sus materiales pictóricos ya nos da una pista para comenzar a analizarlos en relación con su escritura. Tenemos un gesto de la autora frente a su producción que diferencia sus dibujos en dos conjuntos. En el primero (grupo 1) tenemos una serie de dibujos producidos a partir de la primera novela de la serie, Harry Potter and the Philosopher's Stone ${ }^{2}$ [Harry Potter y la piedra filosofal] (1997), y la segunda, Harry Potter and the Chamber of Secrets [Harry Potter y la cámara secreta] (1998). Gracias a testimonios de la autora sabemos que datan del período que va de 1990 a 1995, en el cual escribió la primera novela y planificó la saga, pero no fueron publicados en la edición del texto en 1997. Esta primera veintena de dibujos se dio a conocer esporádicamente en el sitio web de la escritora a lo largo de los años y en algunos documentales televisivos. Finalmente, en una exhibición de 2016

2 En adelante, PS. 
en el Museo Británico y en el sitio web Pottermore, propiedad de Rowling por aquel entonces, se publicó la mayoría de estos dibujos. El segundo conjunto (grupo 2), de treinta imágenes, está conformado por ilustraciones que sí fueron publicadas en los libros Fantastic Beasts and Where to Find Them [Animales fantásticos y dónde encontrarlos] (2001a) y Quidditch Through the Ages [Quidditch a través de los tiempos] (2001b), y otras en The Tales of Beedle The Bard [Los cuentos de Beedle el Bardo] (2008). ${ }^{3}$

¿Qué diferencia instala ese gesto (publicar versus no publicar)? ¿Existe una diferencia material entre ambos conjuntos de ilustraciones? Como en el caso de los artistas que mencionamos en el apartado anterior, prescindir de la obra visual en algunas ediciones de sus trabajos contribuye a la asimilación del proyecto creador personal al texto literario. La pregunta es por qué motivo Rowling no aceptó publicar algunos dibujos del grupo 1, sí los del 2 y luego dar a conocer los del 1 . Responderemos a este interrogante en los siguientes apartados por medio de un análisis de las imágenes y sus vínculos con el texto.

\section{CARACTERIZACIÓN DE LOS DIBUJOS}

Tanto en el grupo 1 como en el 2 predominan dibujos de los personajes. Apenas encontramos en el 1 dos bocetos que remiten a espacios o escenas sin personajes como un croquis de Hogwarts o la secuencia de apertura del callejón Diagon.

Los personajes y sus acciones son protagonistas de la mayoría de las composiciones de escenas o en solitario. Son escasos los dibujos individuales que funcionan a modo de cartilla de personaje o referencia [Figura 1].

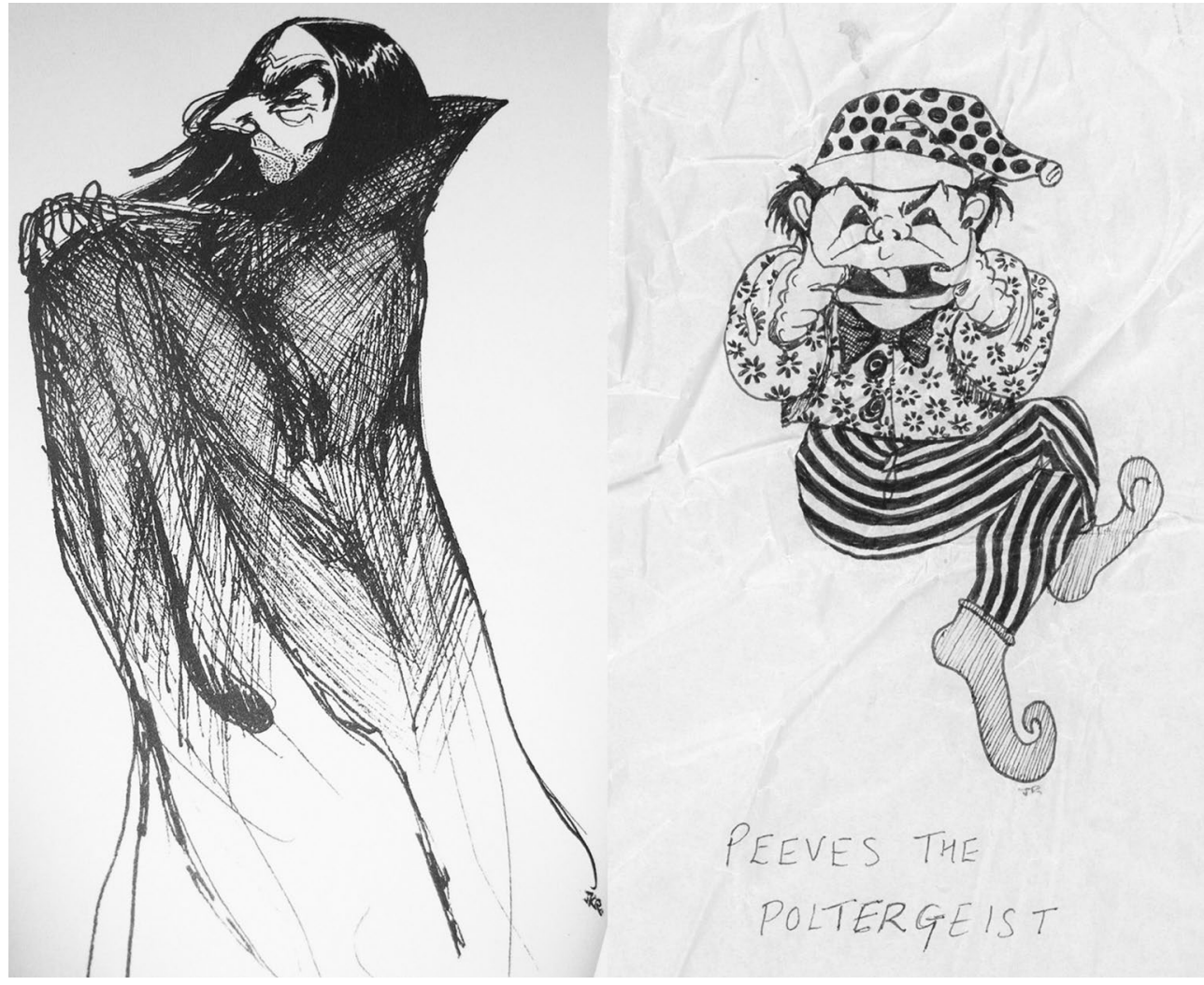

Figura 1. Grupo 1. Diseños de Snape y Peeves. Fuente: Rowling en Pocock (2016)

3 En adelante, FB, QTA y TBB, respectivamente. 
Detectamos un patrón predominante de composición en conjunto, donde se privilegia la acción de los personajes, el movimiento, la actitud, como se ve en la escena del partido de quidditch [Figura 2]. En algunos casos incluso se define a un personaje central en la imagen por contraste con los otros, como se ve en el caso de Snape en primer plano, con actitud desdeñosa frente a los alumnos en segundo plano [Figura 2]. Esta recurrencia compositiva se relaciona con un aspecto de la técnica literaria de Rowling que discutiremos en el siguiente apartado.
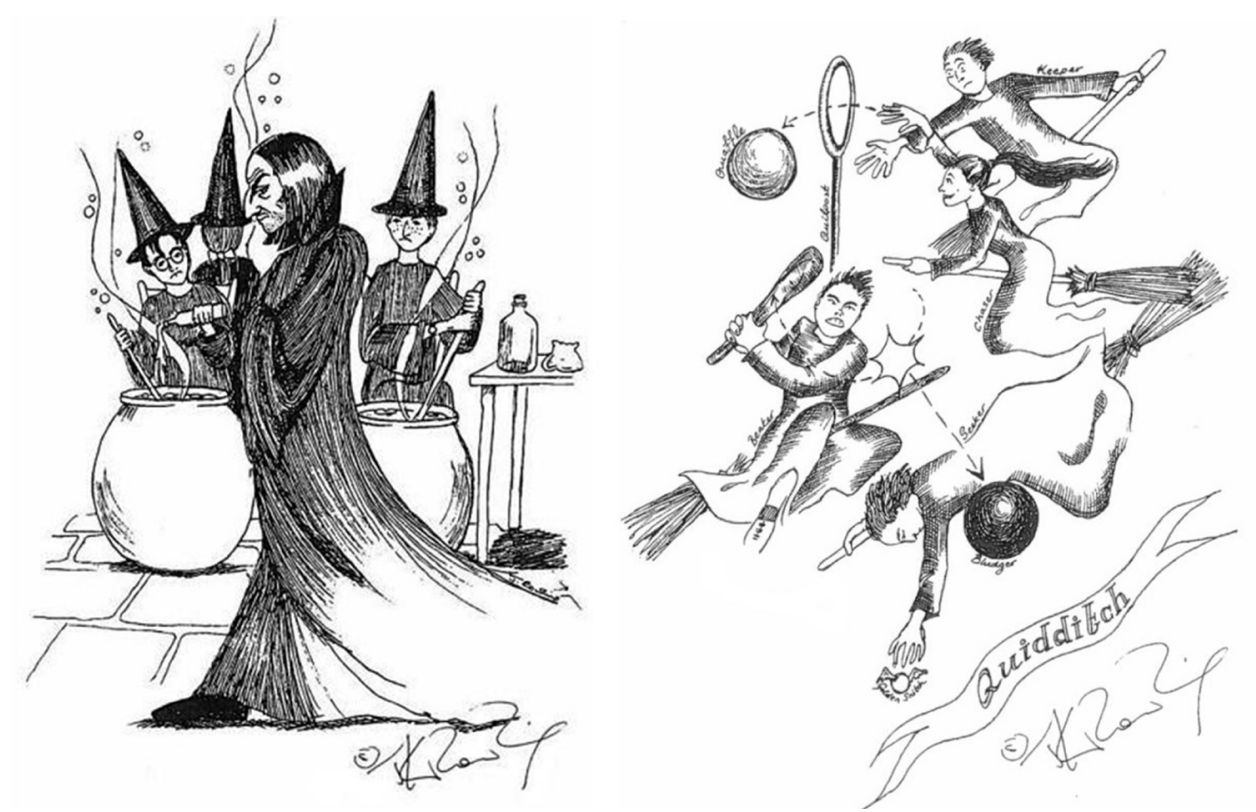

Figura 2. Grupo 1. Clase de Snape y partido de quidditch. Fuente: Rowling en Pocock (2016)

En cuanto a su materialidad, estos dibujos muestran la elección de la birome o pluma y tinta como instrumentos y una técnica de línea y tramado para generar profundidad, sombras y separación en planos. Incluso en los que fueron publicados en QTA y TBB se observa la misma elección [Figura 3]. Esta elección técnica evoca memorias discursivas y asociaciones con otros artistas e, incluso, épocas. En el caso de los dibujos de escenas y de objetos de QTA se remite a los grabados de libros de imprenta tipográfica, una inscripción de parentesco coherente con el verosímil del libro, que simula ser una enciclopedia antigua. Dentro de las ilustraciones publicadas también tenemos las de FB con un estilo aún más simple. Nuevamente, la elección estilística es coherente, pues el libro pretende ser una enciclopedia escrita por un magizoólogo y los dibujos, reproducciones de sus bocetos en cuadernos de campo. 

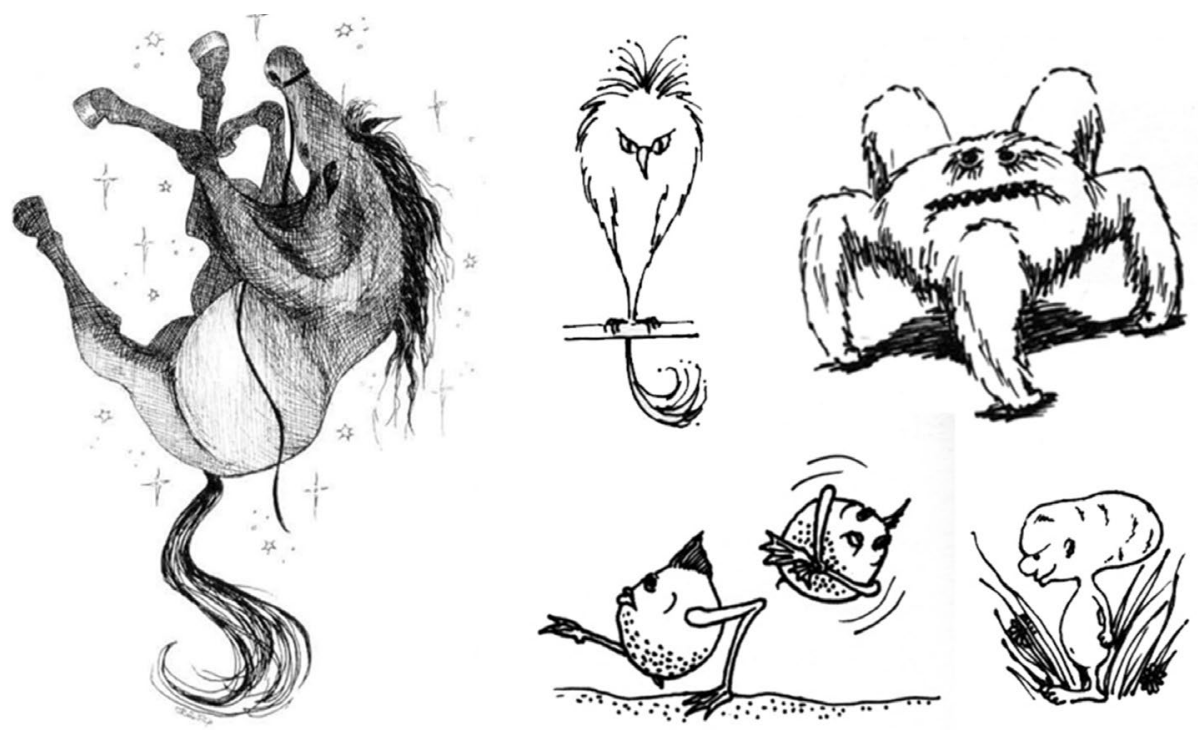

Figura 3. Grupo 2. Escenas de TBB y criaturas de FB. Fuente: Rowling en Pocock (2016)

También detectamos en las figuras 1 a 3 parentescos con ilustraciones como las de John Tenniel o las de otros escritores y dibujantes como Edward Gorey y Rudyard Kipling. La elección de trama y de monocromía se revela como una constante estilística deliberada en los dibujos de Rowling, ya que incluso aparece tanto en los dibujos incluidos en algunos libros como en los no incluidos.

\section{¿QUÉ NOS DICEN LOS DIBUJOS SOBRE LA ESCRITURA?}

Friedman (2007) afirma que "el dibujo y la pintura son utilizados en los procesos creativos de escritores para poder clarificar sus ideas" (p. 15). ${ }^{4}$ Esta hipótesis podría ser válida para explicar bocetos y diagramas, en los cuales se pone en juego la espacialidad y que funcionan como referencias para ordenar la escritura. También podría ser válida para explicar el dibujo sobre la dinámica del quidditch [Figura 2]. Ahora bien, una hipótesis como esa solo impondría una lógica jerárquica a los documentos del proceso creativo según la cual en esas expresiones visuales solo habría una cristalización de ideas cuyo estadio auténtico es textual. ${ }^{5}$

Resulta más productivo analizar los dibujos desde otras consideraciones del geneticismo como la perspectiva de Ferrer (2007) sobre la relación conflictiva de un estado genético con los otros y la presencia de conflictos discursivos en los materiales y el proceso creativo. Esta última categoría propuesta por Élida Lois (2001) apunta a detectar zonas de cambio y las posibles explicaciones para los conflictos discursivos. En esos conflictos y en sus resoluciones se configura ese proyecto creador. Veamos uno de los dibujos de PS [Figura 4].

4 "Some writers have used drawing quite literally as a tool to see. Dostoevsky drew portraits of his characters" (Friedman, 2007, p. 15). Traducción del autor del artículo.

5 Este sesgo interpretativo es lo que Élida Lois $(2001,2005)$ denomina ilusión teleológica: leer los materiales de génesis en función del resultado que conocemos (la novela, en este caso). 


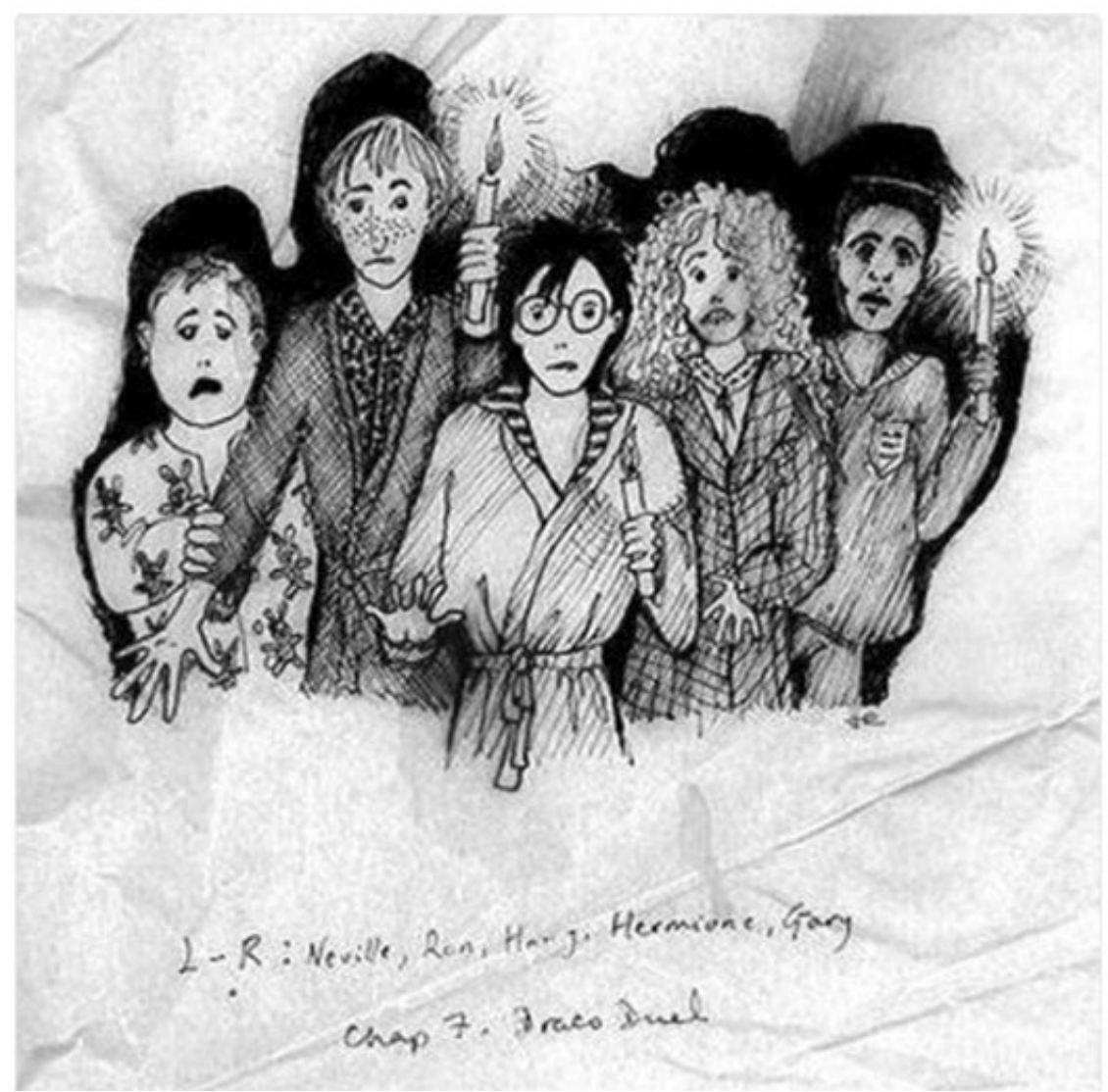

Figura 4. Grupo 1. Escena nocturna de PS. Fuente: Rowling en Pocock (2016)

El epígrafe en el documento identifica a los personajes como a Neville, Ron, Harry, Hermione y Gary respectivamente. El último de ellos, Gary, fue renombrado Dean en la versión editada de la novela. Este cambio forma parte de un conflicto que atraviesa al personaje de Dean a lo largo de toda la saga. No solo se lo eliminó de esta escena en que el grupo deambula por el castillo de noche, sino que se lo hizo para resaltar al personaje de Neville, operación que se repite en otras entregas. Rowling (Pottermore, 2018) mencionó en varias ocasiones la supresión de la historia de este personaje en favor de la de Neville, ya que ambos tenían un pasado familiar muy similar y decidió privilegiar el desarrollo de uno de los dos.

Otro conflicto elocuente tiene que ver aún más con las ilustraciones y sus rasgos visuales más allá del referente que muestran. En la sección anterior mencionamos cómo la técnica y el estilo predominantes en ambos conjuntos de dibujos remitían al de escritores e ilustradores como Kipling o Gorey. Nos preguntábamos antes qué motivó a elegir no publicar el grupo 1 y sí el 2 en ediciones de los libros. La hipótesis que podemos arriesgar es la existencia de un conflicto entre estas imágenes y el verosímil que buscan las novelas de Harry Potter. En otros trabajos (Gagliardi, 2018, 2020) se ha analizado cómo las novelas, si bien pertenecen al género fantástico, utilizan el realismo y el costumbrismo para arraigar a los personajes en situaciones y problemáticas cercanas a las del lector promedio. El estilo de las ilustraciones, próximo al campo de la ilustración infantil y poco mimético, parece oportuno para resaltar los elementos fantásticos y aventureros, pero genera ciertos chispazos con el aspecto costumbrista. Asimismo, dado que las novelas van cobrando mayor seriedad y creciendo en temas y conflictos como sus personajes y lectores, este estilo podría haberse vuelto 
inadecuado. ${ }^{6}$ Si bien el editor de Bloomsbury (la casa editorial inglesa) también recomendó una primera edición no ilustrada, la autora consintió la publicación en dichos términos, por lo cual el gesto también se interpreta como una decisión suya sobre su obra.

La hipótesis que esbozamos se confirma al ver que dibujos del mismo estilo sí fueron publicados en TBB (grupo 2), libro que simula ser una antología de cuentos de hadas. El modo de representación y el estilo de estos dibujos parecen ir en consonancia con los relatos, situados en un tiempo lejano con aires medievales y que tanto en el mundo ficcional de Harry Potter como en el del lector se reconocen como distantes.

Una tercera mirada posible sobre estos dibujos — acaso más tradicional — tiene que ver con las equivalencias semióticas o traducción entre imagen y texto. Con frecuencia, estas relaciones se abordan desde el concepto de écfrasis, la figura retórica que consiste en buscar esos paralelismos o puentes en visualidad y palabra. Los trabajos de Ana Lía Gabrieloni (2006, 2009) sobre la historia del arte (y de pintura y literatura en particular) resultan provechosos tanto para historizar esas relaciones como para advertir los modos en que se han abordado en los estudios comparados.

Si buscamos la écfrasis entre los dibujos y el texto podríamos encontrar similitudes a simple vista. En el caso de la imagen de Harry en la casa de los Dursley [Figura 5] detectamos recursos como la hipérbole en la caracterización contrastiva entre Harry (retratado como un niño delgado, con ropa de talles más grandes que los suyos) y Dudley Dursley, su primo, que aparece en los retratos del fondo, mucho más corpulentos y con rasgos caricaturescos. La novela PS (Rowling, 1997) recuerda en varias ocasiones esta oposición a nivel textual cuando retrata a Dudley con rasgos animales (se lo compara con un cerdo) y a Harry como un niño de menor estatura que otros de su edad, por no mencionar la reiteración de fotografías de uno y la ausencia de las del otro en el muro. Esta equivalencia entre imagen y palabra en todo caso refuerza una caracterización de los personajes en la obra, pero resulta un tanto superficial como indagación en los materiales de archivos. Existe una vinculación más profunda que puede detectarse y que nos acerca a la técnica narrativa de las novelas.

6 Las ediciones inglesas de las novelas contaron con una edición general con ilustraciones de tapa y, posteriormente, con una edición para adultos cuyo arte de tapa resultaba de composiciones fotográficas que eludían mostrar a los personajes. Esa apuesta diferenciada muestra que se tuvo en cuenta la diferencia de público en cuanto al rango etario. 


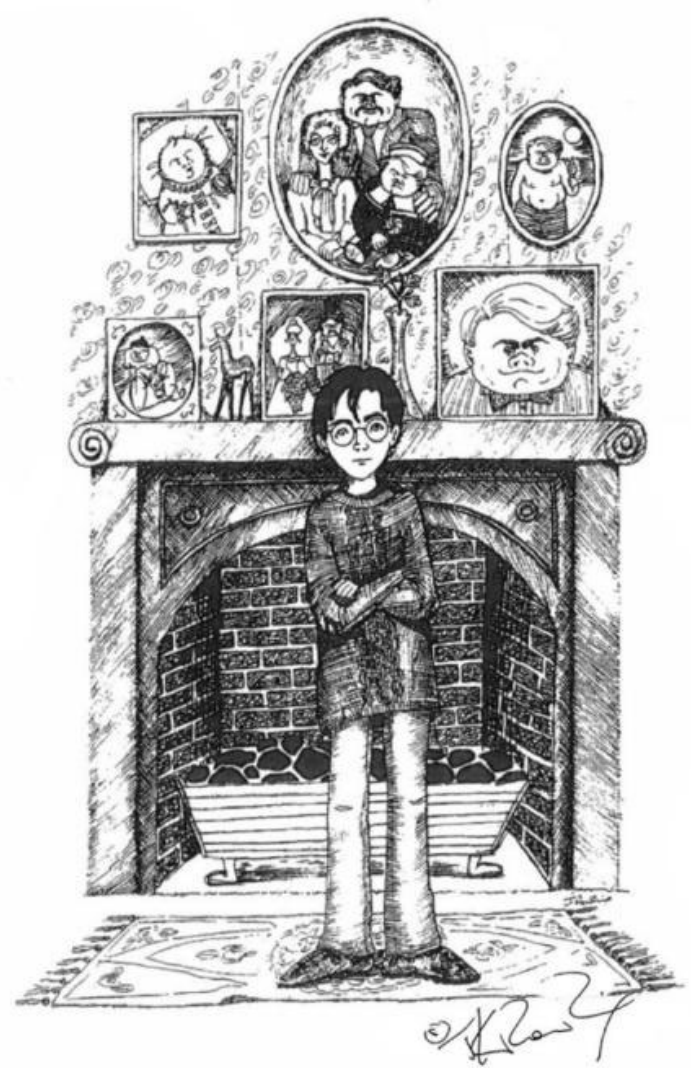

Figura 5. Grupo 1. Harry en PS. Fuente: Rowling en Pocock (2016)

La escritura de Rowling sigue una máxima muy común a los textos policiales y realistas ingleses: show, don't tell, que podríamos traducir como «mostrar en vez de decir» (Gagliardi, 2020). Una y otra vez, el narrador omnisciente de las novelas elige dar acceso al lector por medio de la dimensión visual a las acciones. La narración se concentra en lo que Harry presencia, en cómo percibe al resto de los personajes y los sitios que visita. Estamos ante un caso de focalización donde la visualidad es uno de los mayores indicios para caracterizar a los personajes y entender las situaciones que los involucran. Esta lógica apuesta a que el lector realice inferencias en lugar de que el narrador califique o le ofrezca conclusiones sobre los personajes y la topología. Ese carácter no clausurado en la construcción narrativa y descriptiva aparece en muchos de los dibujos que, como mencionamos, privilegian la interacción entre los personajes y sus actitudes para brindar información sobre los mismos. Show, don't tell se vuelve un principio compositivo que orienta el proyecto creador en ambos tipos de materiales, que ilumina ambos sectores del archivo revelando una coherencia y persistencia entre los estados genéticos.

\section{CONCLUSIONES}

La aproximación a artistas y a obras que recurren a más de un medio expresivo presenta desafíos teóricos y metodológicos para la investigación. Hemos dado cuenta, a lo largo de este trabajo, de las dificultades que entrañan los estudios de este tipo. No obstante, consideramos que zambullirse en la diversidad documental y tratar de recuperar en forma integral la obra de un artista puede iluminar aspectos de su proyecto creador. Sin ignorar los mecanismos sociales y culturales que consagran a un artista en alguna disciplina por sobre otras, la mirada a su producción en otras expresiones artísticas puede contribuir a profundizar la comprensión de su poética. En el caso de Rowling, que hemos tomado en este trabajo, el análisis de su producción pictórica muestra una serie de conflictos y elecciones, de contrapuntos y consonancias, que iluminan aspectos de su técnica literaria (el verosímil que elije construir, la técnica narrativa y descriptiva). Por lo tanto, lejos de ser sobrantes o complementos de la palabra, sus dibujos se revelan como el territorio donde también se dirime su proyecto creador. 


\section{REFERENCIAS}

Bourdieu, P. (2002). Campo de poder, campo intelectual. Ciudad Autónoma de Buenos Aires, Argentina: Montressor.

Ferrer, D. (2007). Quelques remarques sur le couple intertextualité-genèse [Algunas observaciones sobre la pareja intertextualidad-génesis]. En P. Gliffors y M. Schmid (Coords.), La création en acte. Devenir de la critique génétique [La creación en acto. Devenir de la crítica genética] (pp. 205-216). Ámsterdam, Países Bajos: Rodolphi.

Friedman, D. (2007). The Writer's Brush [El pincel del escritor]. Nashville, Estados Unidos: Mid-List Press.

Gabrieloni, A. L. (2006). Écfrasis, transposición, traducción. En G. Cariello, M. I. Barranco y A. Gryn (Eds.), Versiones y cuestiones (pp. 42-49). Recuperado de https://acortar.link/fWajt

Gabrieloni, A. L. (2009). Literatura y artes. En M. Dalmaroni (Coord.), La investigación literaria. Problemas iniciales de una práctica (pp. 125-146). Recuperado de https://acortar. link/3Rh6P

Gagliardi, L. (2018). Intermitencias de lo fantástico en la obra de J. K. Rowling. Épica, policial y sátira en un fantasy híbrido. Luthor, (36). Recuperado de https://acortar.link/2pOap

Gagliardi, L. (2020). Ecos de una saga. Aproximaciones a Harry Potter. Recuperado de https:// acortar.link/DgArs

Genette, G. (1989). Palimpsestos. Madrid, España: Taurus.

Lois, É. (2001). Génesis de escritura y estudios culturales. Introducción a la crítica genética. Ciudad Autónoma de Buenos Aires, Argentina: Edicial.

Lois, É. (2005). De la filología a la genética textual: historia de los conceptos y de las prácticas. En F. Colla (Coord.), Archivos: Cómo editar la literatura latinoamericana del siglo XX (pp. 47- 83). Poitiers, Francia: Centre de Recherches Latino-Américaines.

Nodelman, P. (1988). Words about Pictures. The Narrative Art of Children's Picture Books [Palabras sobre imágenes: el arte narrativo de los libros de imágenes para niños]. Athens, Estados Unidos: University of Georgia Press.

Plaza Chillón, J. L. (2011). La visión plástica de la mujer en los dibujos de Federico García Lorca: aparente ingenuidad, drama surrealista y tragedia expresionista. De Arte, (10), 231-252. http://dx.doi.org/10.18002/da.v0i10.1347

Pocock, E. (25 de agosto de 2016). Original J.K. Rowling Sketches on Pottermore [Bocetos originales de J. K. Rowling en Pottermore] [Entrada de blog]. Recuperado de https:// acortar.link/VrJ2v

Pottermore. (1 de julio de 2018). Shining a Light on Dean Thomas [Echando luz sobre Dean Thomas]. Recuperado de https://www.wizardingworld.com/features/dean-thomashidden-storyline

Rajewsky, I. O. (2005). Intermediality, Intertextuality and Remediation: a Literatura Perspective on Intermediality [Intermedialidad, intertextualidad y remediación: una perspectiva de la literatura sobre la intermedialidad]. Intermédialités, (6), 43-64. https:// doi.org/10.7202/1005505ar

Rougeau, N. R. (2005). Alice's Shadow: Childhood and Agency in Lewis Carroll's Photography, Illustrations, and Alice Text [La sombra de Alice: infancia y agencia en la fotografía, las ilustraciones y el texto de Alice de Lewis Carroll] (Tesis de doctorado). Recuperado de https://acortar.link/mLsE7

Rowling, J. K. (1997). Harry Potter and the Philosopher's Stone [Harry Potter y la piedra filosofal]. Londres, Inglaterra: Bloomsbury.

Rowling, J. K. (1998). Harry Potter and the Chamber of Secrets [Harry Potter y la cámara secreta]. Londres, Inglaterra: Bloomsbury.

Rowling, J. K. (2001a). Fantastic Beasts and Where to Find Them [Animales fantásticos y dónde encontrarlos]. Londres, Inglaterra: Bloomsbury.

Rowling, J. K. (2001b). Quidditch Through the Ages [Quidditch a través de los tiempos]. Londres, Inglaterra: Bloomsbury.

Rowling, J. K. (2008). The Tales of Beedle The Bard [Los cuentos de Beedle el Bardo]. Londres, Inglaterra: Bloomsbury. 
Stedile Luna, V. (2013). He encontrado una nueva forma de ser humano. La escritura del cuerpo como intervención política y cultural en la poética de Violeta Parra (Tesis de licenciatura). Recuperado de https://acortar.link/or8Gi 